\title{
Relationship Between Cytokine Gene Polymorphisms and Risk of Postoperative Pneumonia with Esophageal Cancer
}

\author{
Kazuhiko Sakamoto $\cdot$ Masaaki Oka • \\ Shigehumi Yoshino • Shoichi Hazama • Shigeru Takeda • \\ Kiyoshi Yoshimura $\cdot$ Naoko Okayama $\cdot$ Yuji Hinoda
}

Received: 23 December 2013 / Accepted: 21 April 2014 / Published online: 8 May 2014

(C) 2014 The Author(s). This article is published with open access at Springerlink.com

\begin{abstract}
Background We retrospectively evaluated the relationship between cytokine gene polymorphisms and development of postoperative pneumonia after esophagectomy.

Methods In 120 patients who underwent esophagectomy, serum samples were obtained to measure levels of serum interleukin (IL)-6 and IL-10 at four time points (preoperatively, postoperative day (POD)0, POD1, and POD3). DNA extracted from peripheral blood in all patients was analyzed to determine polymorphisms of cytokines such as tumor necrosis factor- $\alpha-1031 \mathrm{~T} /$ C, IL-1 $\beta-511 \mathrm{C} / \mathrm{T}$, IL-6 -634C/G, and IL-10 -819 T/C.

Results Postoperative pneumonia arose in 34 patients ( $28.3 \%$ ). Perioperative serum IL-10 levels were significantly higher for IL$10-819 \mathrm{C} / \mathrm{T}+\mathrm{C} / \mathrm{C}$ genotypes than for $\mathrm{T} / \mathrm{T}$ genotypes (POD0 $16.7 \pm 2.84$ vs. $8.54 \pm 0.87 \mathrm{pg} / \mathrm{ml}, p=0.0002 ; \mathrm{POD} 114.0 \pm 2.64 \mathrm{vs}$. $8.8 \pm 0.87 \mathrm{pg} / \mathrm{ml}, p=0.0143$; POD3 $8.9 \pm 2.67$ vs. $4.4 \pm 0.52 \mathrm{pg} / \mathrm{ml}, p=0.0076$ ). The frequency of the IL-10 $-819 \mathrm{~T} / \mathrm{T}$ genotype was significantly higher in patients with postoperative pneumonia than in patients without pneumonia $(p=0.0323)$. Multivariate analysis of factors such as sex, smoking, length of operation, field of lymph node dissection, and IL-10 polymorphism identified IL-10 polymorphism as independent predictor of postoperative pneumonia.

Conclusions Patients with IL-10 -819 T/T genotype may be at high risk for postoperative pneumonia after esophagectomy.
\end{abstract}

Keywords IL-10 polymorphism · Postoperative pneumonia · Esophagectomy

\section{Introduction}

Surgery for esophageal cancer is one of the most invasive gastrointestinal surgeries, ${ }^{1,2}$ and perioperative mortality rates

K. Sakamoto $\cdot$ M. Oka $(\bowtie) \cdot$ S. Yoshino $\cdot$ S. Hazama $\cdot$ S. Takeda $\cdot$ K. Yoshimura

Department of Digestive Surgery and Surgical Oncology, Yamaguchi University Graduate School of Medicine, 1-1-1 Minami-Kogushi, Ube, Yamaguchi 755-8505, Japan

e-mail: 2geka-1@yamaguchi-u.ac.jp

N. Okayama $\cdot$ Y. Hinoda

Division of Laboratory, Yamaguchi University Hospital, Yamaguchi, Japan

Y. Hinoda

Department of Oncology and Laboratory Medicine, Yamaguchi University Graduate School of Medicine, Yamaguchi, Japan remain in the range of 3-10\%. ${ }^{3-5}$ In the case of esophageal cancer, marked elevations in cytokine levels are observed perioperatively, inducing a systemic inflammatory response syndrome (SIRS). ${ }^{6} 7$ Such hypercytokinemia produces excessive stress and may trigger postoperative complications. ${ }^{8}$ The lungs is one of the main organs of neutrophil sequestration under conditions of SIRS. ${ }^{9-12}$ Abe et al. reported that transthoracic esophagectomy causes an increase in interleukin (IL)6 production from bronchial and alveolar epithelial cells lining the airway, and local response of lung tissue may be one source of increased serum IL-6 after esophagectomy in humans. ${ }^{13}$ The clinical effects of an immune response are orchestrated by numerous pro-inflammatory, inflammatory, and anti-inflammatory cytokines. Tumor necrosis factor (TNF)- $\alpha$ is a major mediator and amplifier of immune responses to infectious challenges. Azim et al. recently reported that the TNF- $\alpha-308$ polymorphism contributes to infectious complications after esophagectomy. ${ }^{14}$ Moreover, associations between infection and genetic polymorphisms have been reported for other cytokines, including IL-1 $\beta$, IL-6, and IL-10. ${ }^{15^{-18}}$ These findings 
suggest that patient genotype may influence susceptibility to postoperative infection.

We have a considerable interest in whether factors such as these polymorphisms might affect the postoperative infection, particularly in terms of the effects on postoperative pneumonia. We selected TNF- $\alpha$, IL-1 $\beta$, IL-6, and IL-10 as representative pro-inflammatory, inflammatory, and anti-inflammatory cytokines and investigated the gene promoter polymorphisms of TNF- $\alpha-1031 \mathrm{~T}>\mathrm{C}(\mathrm{rs} 1799964), \mathrm{IL}-1 \beta-511 \mathrm{~T}>\mathrm{C}$ (rs3087258), IL-6 -634G $>$ C (rs1800796), and IL-10 $819 \mathrm{~T}>\mathrm{C}$ (rs1800871); all of which have been reported to influence cytokine production. ${ }^{18-22}$ The purpose of this study was to assess whether cytokine promoter gene polymorphisms are associated with the following: (1) perioperative cytokine production and (2) postoperative pneumonia following esophagectomy.

\section{Methods}

Patients

This was a retrospective cohort study that included patients treated for esophageal cancer between 1997 and 2011. Participants comprised 120 consecutive Japanese patients (105 men and 15 women) with thoracic esophageal cancer who underwent curative esophagectomy and reconstruction with gastric mobilization via a posterior mediastinal or retrosternal route by right posterolateral thoracotomy and laparotomy consecutively in the Department of Digestive Surgery and Surgical Oncology at Yamaguchi University Graduate School of Medicine. These patients underwent dissection of two (mediastinal and abdominal) or three (bilateral neck, mediastinal, and abdominal) lymph node fields. Patients who received neoadjuvant treatment or underwent reconstruction with small intestine or colon mobilization were excluded. We introduced thoracoscopic procedures in a prone position from 2008 and excluded these procedures from the present study. In all cases, diagnoses of esophageal squamous cell cancer were confirmed preoperatively on the basis of histopathological reports. The clinicopathological definition of thoracic esophageal cancer was based on the International Union against Cancer tumor-node-metastasis (TNM) classification of malignant tumors (6th edition). Written informed consent was obtained from all study patients. The study protocol was approved by the Institutional Review Board for the Use of Human Subjects at Yamaguchi University Graduate School of Medicine.

\section{Perioperative Management}

We performed perioperative management as follows. At the first visit to our hospital, all patients were instructed to quit smoking and respiratory rehabilitation was started at the same time. As prophylactic antibiotics, patients received cefazolin $1 \mathrm{~g}$ by intravenous infusion for $30 \mathrm{~min}$ before the operation. An additional dose was administered if the operation was prolonged beyond $3 \mathrm{~h}$. Patients received the same antibiotics plus further treatment at 12-h intervals, for a total of 5 days. For nutritional support, enteral nutrition was provided via jejunostomy from $6 \mathrm{~h}$ postoperatively, and the dose was increased step-by-step to $2,000 \mathrm{kcal} /$ day up to postoperative day (POD) 7. All patients were admitted to the intensive care unit and placed on prophylactic mechanical ventilation. The timing of extubation was decided according to the results of bronchoscopy, blood gas analysis, and chest radiography. The criteria for extubation were as follows: (1) arterial oxygen pressure $>100 \mathrm{mmHg}$ with inspired fraction of oxygen $\left(\mathrm{FiO}_{2}\right) 0.4$ and (2) absence of atelectasis on bronchoscopic view or radiography.

\section{Postoperative Complications}

Postoperative complications were defined as follows. Postoperative pneumonia was diagnosed by the presence of pyrexia $>38{ }^{\circ} \mathrm{C}$ within 2 weeks postoperatively and either positive sputum cultures or clear clinical or radiological evidence of consolidation. Anastomotic leakage was diagnosed by gastrography and clinical features. Postoperative wound infection was defined as a systemic response to the presence of an infectious agent supported by clinical and laboratory evidence, where laboratory evidence means positive culture results. Cardiac complications including arrhythmia, angina, or heart failure were diagnosed by a cardiologist.

\section{Serum Cytokines}

Serum samples were obtained at four time points (preoperatively, end of the operation (POD0), POD1, and POD3) and stored at $-80{ }^{\circ} \mathrm{C}$ until use. Serum IL- 6 and IL-10 levels were measured using commercially available enzyme-linked immunosorbent assay kits (BioSource International, Camarillo, CA). Samples were prepared and tested in duplicate according to the protocol recommended by the manufacturer.

\section{DNA Specimens and Genotyping}

For DNA analysis, $7 \mathrm{ml}$ of peripheral blood was obtained from all patients. DNA was isolated by a conventional NaI method and stored at $4{ }^{\circ} \mathrm{C} .{ }^{23}$ All polymorphisms were identified with the tetra-primer amplification refractory mutation system-polymerase chain reaction (ARMS-PCR), and details of primers and PCR conditions have been described in the literature. ${ }^{2426}$ 


\section{Statistical Analysis}

Data are expressed as mean values \pm standard error and were analyzed using the Mann-Whitney $U$ test. Categorical data were analyzed using the $\chi^{2}$ test or Fisher's exact test. Differences in genotype frequency were analyzed using the $\chi^{2}$ test or Fisher's exact test of independence, with which, each of the genotype frequencies was evaluated to determine whether it was consistent with expected Hardy-Weinberg proportions. Because homozygotes for the rare allele were too few to perform a $2 \times 3 \chi^{2}$ test or Fisher's exact test, homozygotes of the dominant alleles and variant carriers were compared by $2 \times 2$ test. Variables with a $p<0.2$ in the univariate analysis that were potentially predictive of postoperative pneumonia were then entered into the multivariate logistic regression model. Odds ratio $(\mathrm{OR})$ and $95 \%$ confidence interval (CI) were also calculated. A value of $p<0.05$ was considered statistically significant. All analyses were performed using StatView version 5.0 statistical software (SAS Institute, Cary, NC).

\section{Results}

In all 120 patients studied, the frequency of postoperative pneumonia was $28.3 \%$ (34 of 120 patients). In terms of other complications, 14 patients $(11.7 \%)$ developed wound infection, 8 patients $(6.7 \%)$ developed anastomotic leakage, and 25 patients $(20.8 \%)$ developed cardiac complications. Perioperative patient- and tumor-related factors and other complications were compared between groups with and without postoperative pneumonia (Table 1). The proportion of males was significantly higher among patients with pneumonia $(97.1 \%)$ than among patients without pneumonia $(82.6 \%$;
Table 1 Patient characteristics in the two groups

Data are presented as mean+standard error or absolute numbers

$F E V$ forced expiratory volume, $C R P$ C-reactive protein, UICC International Union Against Cancer

\begin{tabular}{|c|c|c|c|}
\hline & Pneumonia $+(n=34)$ & Pneumonia $-(n=86)$ & $p$ value \\
\hline Age & $63.7 \pm 8.9$ & $63.0 \pm 9.2$ & 0.337 \\
\hline \multicolumn{4}{|l|}{ Gender } \\
\hline Male & 33 & 71 & \\
\hline Female & 01 & 15 & 0.0384 \\
\hline Body mass index $\left(\mathrm{kg} / \mathrm{m}^{2}\right)$ & $21.0 \pm 3.0$ & $21.1 \pm 3.0$ & 0.954 \\
\hline \multicolumn{4}{|l|}{ Smoking } \\
\hline Yes & 32 & 71 & \\
\hline No & 02 & 15 & 0.147 \\
\hline FEV1.0 \% & $73.2 \pm 12.2$ & $73.1 \pm 8.8$ & 0.592 \\
\hline Preoperative CRP (mg/dl) & $0.82 \pm 2.4$ & $0.32 \pm 0.47$ & 0.765 \\
\hline \multicolumn{4}{|l|}{ Tumor locations } \\
\hline Upper & 04 & 09 & \\
\hline Middle & 21 & 44 & \\
\hline Lower & 09 & 33 & 0.465 \\
\hline \multicolumn{4}{|l|}{ UICC stage (pathological) } \\
\hline I and II & 21 & 50 & \\
\hline III and IV & 13 & 36 & 0.716 \\
\hline Length of operation (min) & $463 \pm 100$ & $433 \pm 99$ & 0.0679 \\
\hline Blood loss (g) & $820 \pm 913$ & $548 \pm 267$ & 0.283 \\
\hline \multicolumn{4}{|l|}{ Field of lymph node dissection } \\
\hline 2 (mediastinum and abdomen) & 22 & 68 & \\
\hline 3 (bilateral neck, mediastinum, and abdomen) & 12 & 18 & 0.102 \\
\hline \multicolumn{4}{|l|}{ Wound infection } \\
\hline Yes & 5 & 09 & \\
\hline No & 29 & 77 & 0.536 \\
\hline \multicolumn{4}{|l|}{ Anastomotic leakage } \\
\hline Yes & 03 & 05 & \\
\hline No & 31 & 81 & 0.686 \\
\hline \multicolumn{4}{|l|}{ Cardiac complications } \\
\hline Yes & 09 & 16 & \\
\hline No & 25 & 70 & 0.339 \\
\hline
\end{tabular}


$p=0.0384$ ). The proportions of smoking, 3-field lymph node dissection, and the length of operation tended to be higher among patients with pneumonia than among patients without pneumonia ( $p=0.147, p=0.102$, and $p=0.0679$, respectively).

No relationship was seen between perioperative serum IL-6 levels and polymorphisms (Fig. 1). Perioperative serum IL-10 levels were significantly higher for IL-10 $-819 \mathrm{C} / \mathrm{T}+\mathrm{C} / \mathrm{C}$ genotypes than for $\mathrm{T} / \mathrm{T}$ genotypes (POD0 $16.7 \pm 2.84 \mathrm{vs}$. $8.54 \pm 0.87 \mathrm{pg} / \mathrm{ml}, p=0.0002$; POD1 $14.0 \pm 2.64$ vs. $8.8 \pm$ $0.87 \mathrm{pg} / \mathrm{ml}, p=0.0143$; POD3 $8.9 \pm 2.69$ vs. $4.4 \pm 0.52 \mathrm{pg} / \mathrm{ml}$, $p=0.0076$ ) (Fig. 2).

Among the cytokine promoter gene polymorphisms analyzed, a significant association with pneumonia was found for IL-10 -819 T/C. The frequency of the IL-10 -819 T/T genotype was significantly higher in patients with pneumonia than in those without pneumonia $(p=0.0323)$ (Table 2).

Although no relationship was seen between postoperative serum IL-10 levels and Il-10 polymorphisms in patients with pneumonia, these levels were significantly higher for IL-10 -
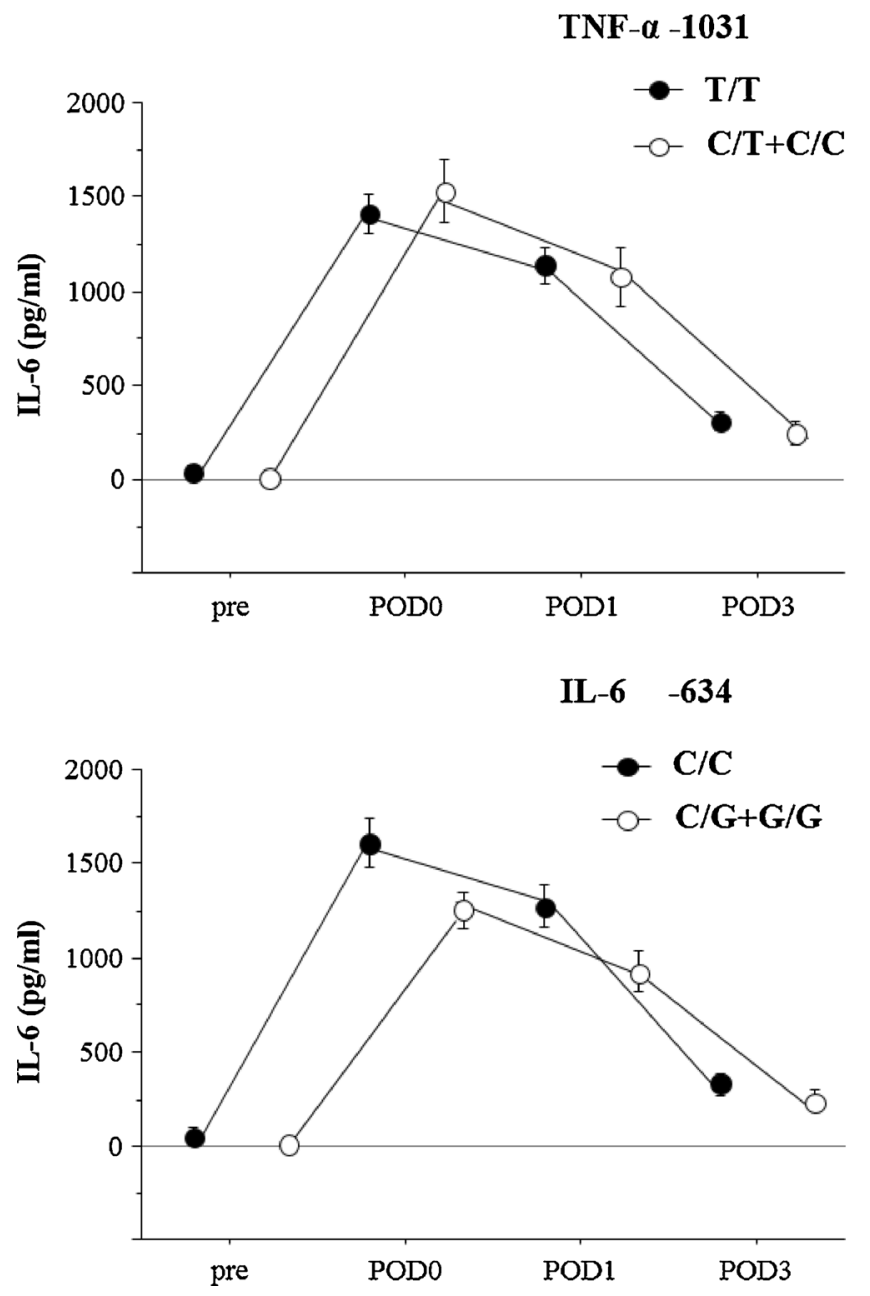

Fig 1 Pre- and postoperative serum levels of interleukin (IL)-6. The relationship between polymorphism of the cytokine genes (tumor necrosis factor (TNF)- $\alpha-1031$ T/C, IL-1 $\beta-511 \mathrm{C} / \mathrm{T}$, IL-6 -634C/G, IL-10 819 T/C) and IL-6 level in 120 patients after esophagectomy. Solid circles
$819 \mathrm{~T} / \mathrm{C}+\mathrm{C} / \mathrm{C}$ genotypes than for $\mathrm{T} / \mathrm{T}$ genotypes in patients without pneumonia (Table 3 ).

Clinicopathological variables, including sex (male vs. female), smoking (yes vs. no), length of operation, field of lymph node dissection (three vs. two), and IL-10 -819 polymorphism $(\mathrm{T} / \mathrm{T}$ vs. $\mathrm{C} / \mathrm{T}+\mathrm{C} / \mathrm{C})$ were entered into a multivariate logistic regression model to identify factors influencing pneumonia (Table 4). Only IL-10 -819 polymorphism was significantly associated with pneumonia $(p=0.0334, \mathrm{OR}=2.68$, $95 \% \mathrm{CI}=1.08-6.67)$.

\section{Discussion}

This study revealed that IL-10 -819 polymorphism is associated with postoperative pneumonia in Japanese patients with esophageal cancer. The IL-10 -819 TT genotype is related to lower perioperative production of serum IL-10 level. No associations with any other cytokine polymorphism for

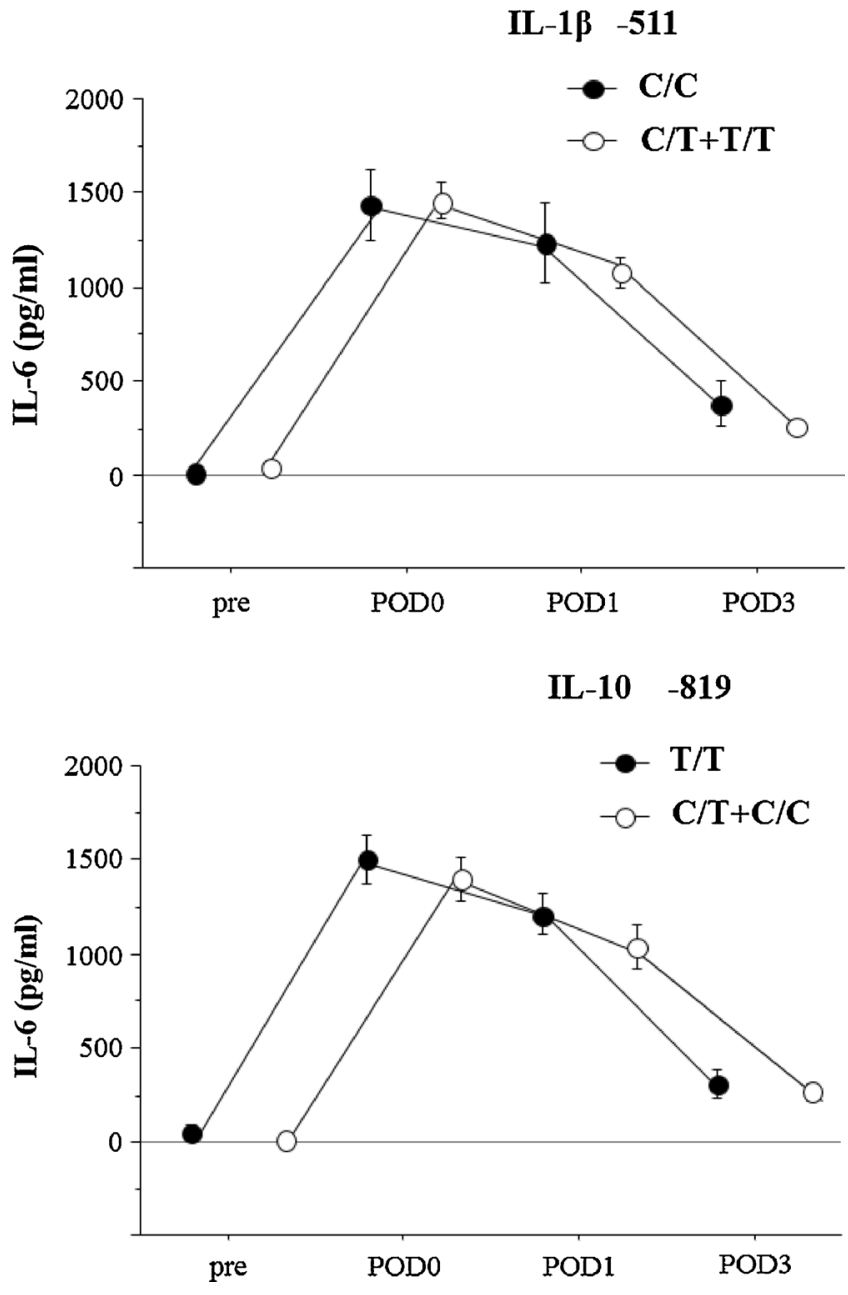

indicate wild-type polymorphism, open circles indicate variant-type polymorphism. Values are expressed as mean \pm standard error. Statistically significant according to the Mann-Whitney $U$ test. $I L$ interleukin, TNF tumor necrosis factor, $P O D$ postoperative day 
TNF- $\alpha-1031$

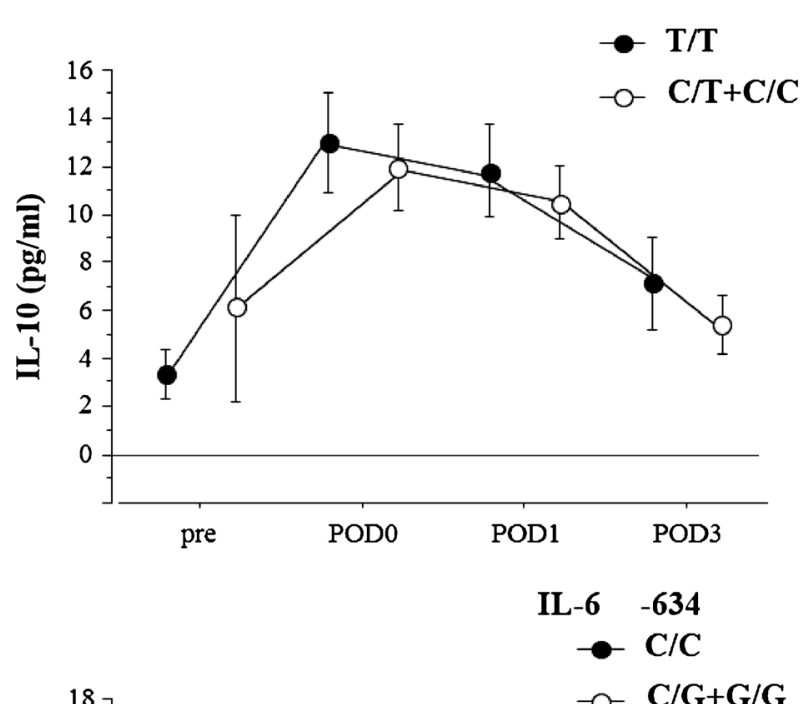

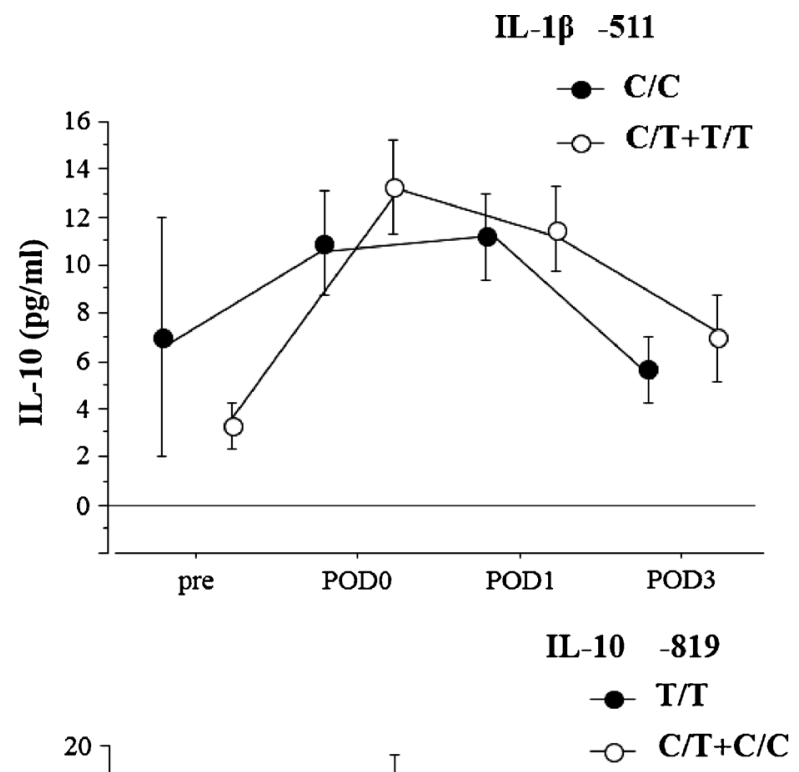

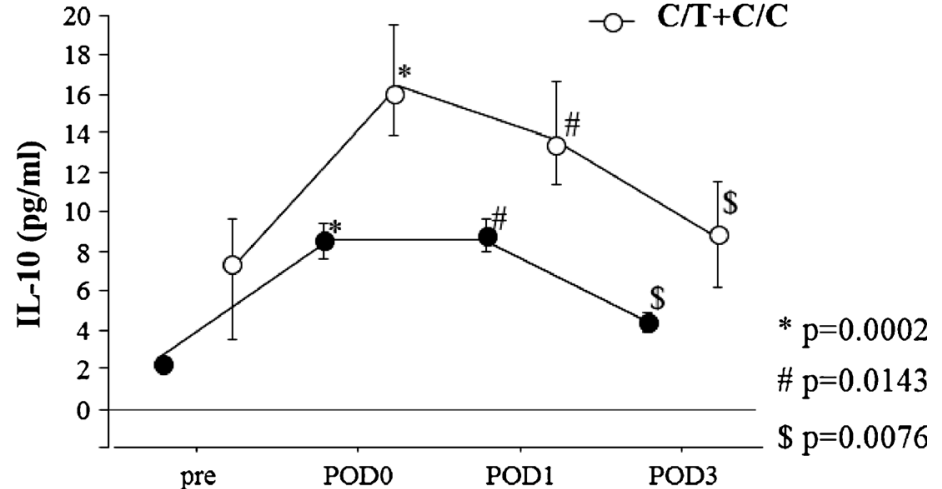

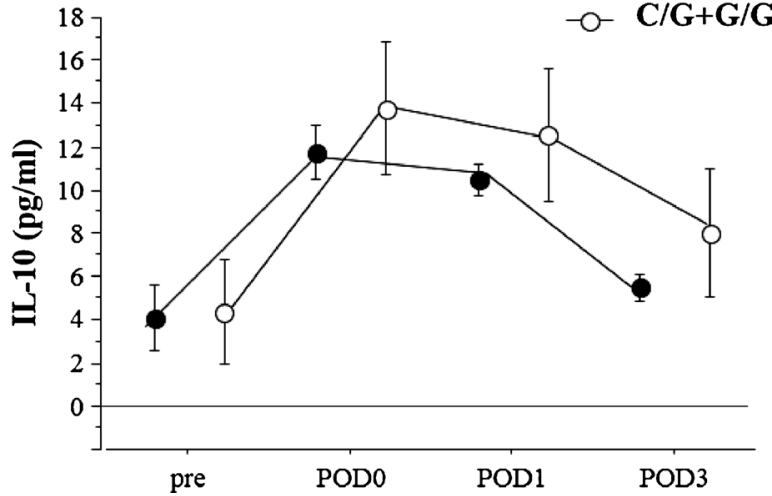

Fig 2 Pre- and postoperative serum levels of interleukin (IL)-10. The relationship between polymorphism of cytokine genes (tumor necrosis factor (TNF)- $\alpha-1031$ T/C, IL-1 $\beta-511 \mathrm{C} / \mathrm{T}$, IL-6 -634C/G, IL-10 -819 T/ C) and IL-10 level in 120 patients after esophagectomy. Solid circles indicate wild-type polymorphism, open circles indicate variant-type

TNF- $\alpha$, IL-1 $\beta$, or IL- 6 were evident. Presence of the IL-10 819 TT genotype seems to confer lower IL-10 release in response to surgical stress and an increased risk of postoperative pneumonia.

Under highly inflammatory conditions such as following esophagectomy, a genotype associated with high antiinflammatory response may be protective against the development of postoperative respiratory inflammation. IL-10 is a polymorphism. Values are expressed as mean \pm standard error. Statistically significant according to the Mann-Whitney $U$ test. ${ }^{*} p=0.0002$; ${ }^{\#} p=0.0143 ;{ }^{\$} p=0.0076$. IL interleukin, $T N F$ tumor necrosis factor, $P O D$ postoperative day

potent endogenous anti-inflammatory cytokine that decreases lung inflammation, partly on the basis of TNF- $\alpha$ and IL- $1 \beta .{ }^{27}$ Alveolar macrophages produce significant amounts of IL$10 .{ }^{28,29}$ Morita reported that IL-10 production after rat thoracotomy was higher from the collapsed lung than from the uncollapsed lung, possibly reflecting suppression of IL-6 production from the collapsed lung. ${ }^{30}$ These findings are supported by the clinical observation that decreased IL-10
Table 2 Genotype distribution in the postoperative pneumonia

$T N F$ tumor necrosis factor, $I L$ interleukin

\begin{tabular}{lllll}
\hline Cytokine polymorphism & Pneumonia $+(n=34)$ & Pneumonia $-(n=86)$ & $p$ value \\
\hline TNF- $\alpha-1031$ & $\mathrm{~T} / \mathrm{T}$ & 21 & 62 & 0.27 \\
& $\mathrm{~T} / \mathrm{C}+\mathrm{C} / \mathrm{C}$ & 13 & 24 & \\
IL-1 $\beta-511$ & $\mathrm{C} / \mathrm{C}$ & 08 & 26 & 0.463 \\
& $\mathrm{C} / \mathrm{T}+\mathrm{T} / \mathrm{T}$ & 26 & 60 & \\
IL-6 -634 & $\mathrm{G} / \mathrm{G}$ & 20 & 47 & 0.678 \\
& $\mathrm{G} / \mathrm{C}+\mathrm{C} / \mathrm{C}$ & 14 & 39 & 0.0323 \\
IL-10 -819 & $\mathrm{T} / \mathrm{T}$ & 22 & 37 & \\
& $\mathrm{~T} / \mathrm{C}+\mathrm{C} / \mathrm{C}$ & 12 & 49 & \\
\hline
\end{tabular}


Table 3 Trend in serum IL-10 levels according to IL-10 -819 polymorphism with and without pneumonia

\begin{tabular}{|c|c|c|c|c|c|c|}
\hline & \multicolumn{2}{|c|}{ Pneumonia $\pm(n=34)$} & \multirow[t]{2}{*}{$p$ value } & \multicolumn{2}{|c|}{ Pneumonia $-(n=86)$} & \multirow[t]{2}{*}{$p$ value } \\
\hline & $\mathrm{T} / \mathrm{T}(n=22)$ & $\mathrm{T} / \mathrm{C} \pm \mathrm{C} / \mathrm{C}(n=12)$ & & $\mathrm{T} / \mathrm{T}(n=37)$ & $\mathrm{T} / \mathrm{C} \pm \mathrm{C} / \mathrm{C}(n=49)$ & \\
\hline \multicolumn{7}{|c|}{ Serum IL-10 level (pg/ml) } \\
\hline POD0 & $9.5 \pm 1.6$ & $17.4 \pm 5.3$ & 0.65 & $8.0 \pm 1.0$ & $16.5 \pm 3.3$ & $<0.01$ \\
\hline POD1 & $10.1 \pm 1.8$ & $10.9 \pm 4.0$ & 0.62 & $8.0 \pm 0.9$ & $14.8 \pm 3.2$ & $<0.01$ \\
\hline POD3 & $5.3 \pm 0.9$ & $6.2 \pm 3.0$ & 0.77 & $3.8 \pm 0.6$ & $9.6 \pm 3.3$ & $<0.01$ \\
\hline
\end{tabular}

Data are presented as mean \pm standard error

$I L$ interleukin, $P O D$ postoperative day

concentration in bronchoalveolar lavage fluid is associated with worse outcomes in patients with the acute respiratory distress syndrome. ${ }^{31}$ IL-10 therapy increased survival both in a rabbit Pseudomonas aeruginosa pneumonia model and in a murine pneumococcal pneumonia model. ${ }^{32}$ Those results indicate that IL-10 is a key regulator of the degree of inflammation in the setting of acute lung infection or inflammation.

The current finding that the high IL-10-producing -819C allele is protective against postoperative respiratory inflammation following esophagectomy is consistent with the role of intense inflammation. Lowe et al. reported that the IL-10 -592 CC polymorphism was associated with higher IL-10 release under lipopolysaccharide stimulation and lower mortality in critically ill patients. ${ }^{20}$ Similar frequencies were obtained for $819 \mathrm{~T} / \mathrm{C}$ and $-592 \mathrm{~A} / \mathrm{C}$ in all types of participants, indicating complete linkage. ${ }^{33}$ Those findings are consistent with our own results. However, in critically ill patients with sepsis, the mortality rate was significantly higher in patients with the 592 CC genotype than in those with the -592 AA genotype. ${ }^{33}$ The overall balance between pro- and anti-inflammatory responses is important in response to injury or surgery. In patients with sepsis, a genotype associated with high IL-10 production may lead to greater immunosuppression, resulting in more severe disease burden and outcomes. In contrast, the present findings were obtained following esophagectomy. In such cases, a genotype associated with high IL-10 may have beneficial modulating effects. The notion that a high IL-10-

Table 4 Logistic regression predicting development of postoperative pneumonia

\begin{tabular}{llll}
\hline & OR & $95 \%$ CI & $p$ value \\
\hline Gender (male vs. female) & 4.64 & $0.491-43.9$ & 0.18 \\
Smoking (yes vs. no) & 1.35 & $0.235-7.72$ & 0.738 \\
Length of operation (min) & 1.002 & $0.998-1.007$ & 0.276 \\
Field of lymph node dissection (3 vs. 2) & 1.43 & $0.516-3.97$ & 0.491 \\
IL-10 Genotype (T/T vs. C/T+C/C) & 2.68 & $1.08-6.67$ & 0.0334 \\
\hline
\end{tabular}

$O R$ odds ratios, $C I$ confidence interval, $I L$ interleukin producing $-819 \mathrm{C}$ allele may not be universally detrimental appears reasonable.

Azim et al. reported that not IL-10 -819 T/C but TNF- $\alpha$ $308 \mathrm{G} / \mathrm{A}$ polymorphism contributes to infectious complications after esophagectomy. ${ }^{14}$ That result differs from the findings of the present study. However, the frequency of the -308 A allele for TNF- $\alpha$ is much lower in Japanese populations $(1.1-1.3 \%)$ than in Caucasians (10-18\%). ${ }^{33-36}$ Furthermore, the frequency of the -819 C allele of IL-10 in Japanese (30.5$33.6 \%$ ) was lower than in Caucasians (79-82\%). ${ }^{20,33,37}$ These results suggest that considering the influence of ethnic differences in gene polymorphism may be important. Further studies on gene polymorphisms in different ethnicities are needed to allow tailoring of specific therapies. Identifying IL-10 polymorphisms in patients prior to esophagectomy may influence management decisions where controversy currently exists, such as the use of other therapeutic strategies. For example, whether steroids should be used to treat patients perioperatively remains unresolved. ${ }^{38}$ Some patients may benefit, while others may not, depending on individual genotypes. Genotyping this IL-10 polymorphism in patients following esophagectomy may allow better risk stratification and tailoring of specific therapies to different risk groups.

Conflict of Interest There are no conflicts of interest.

Open Access This article is distributed under the terms of the Creative Commons Attribution License which permits any use, distribution, and reproduction in any medium, provided the original author(s) and the source are credited.

\section{References}

1. Haga Y, Beppu T, Doi K, et al. Systemic inflammatory response syndrome and organ dysfunction following gastrointestinal surgery. Critical care medicine 1997; 25(12): 1994-2000.

2. Ono S, Aosasa S, Mochizuki H. Effects of a protease inhibitor on reduction of surgical stress in esophagectomy. Am J Surg 1999; 177(1): 78-82. 
3. Poon RT, Law SY, Chu KM, Branicki FJ, Wong J. Esophagectomy for carcinoma of the esophagus in the elderly: results of current surgical management. Annals of surgery 1998; 227(3): 357-64.

4. Bailey SH, Bull DA, Harpole DH, et al. Outcomes after esophagectomy: a ten-year prospective cohort. Ann Thorac Surg 2003; 75(1): 217-22; discussion 22.

5. Atkins BZ, Shah AS, Hutcheson KA, et al. Reducing hospital morbidity and mortality following esophagectomy. Ann Thorac Surg 2004; 78(4): 1170-6; discussion 70-6.

6. Maeba $\mathrm{T}$, Maeta $\mathrm{H}$, Usuki $\mathrm{H}$, et al. Increase in portal blood interleukin- 6 soon after the commencement of digestive surgery. Surg Today 1996; 26(11): 890-4.

7. Hisano S, Sakamoto K, Ishiko T, Kamohara H, Ogawa M. IL6 and soluble IL-6 receptor levels change differently after surgery both in the blood and in the operative field. Cytokine 1997; 9(6): 447-52.

8. Roumen RM, Hendriks T, van der Ven-Jongekrijg J, et al. Cytokine patterns in patients after major vascular surgery, hemorrhagic shock, and severe blunt trauma. Relation with subsequent adult respiratory distress syndrome and multiple organ failure. Annals of surgery 1993; 218(6): 769-76.

9. Kitagawa Y, Van Eeden SF, Redenbach DM, et al. Effect of mechanical deformation on structure and function of polymorphonuclear leukocytes. J Appl Physiol 1997; 82(5): 1397-405.

10. Lee WL, Downey GP. Neutrophil activation and acute lung injury. Curr Opin Crit Care 2001; 7(1): 1-7.

11. Razavi HM, Wang le F, Weicker S, et al. Pulmonary neutrophil infiltration in murine sepsis: role of inducible nitric oxide synthase. American journal of respiratory and critical care medicine 2004; 170(3): 227-33.

12. Lin X, Yang H, Sakuragi T, et al. Alpha-chemokine receptor blockade reduces high mobility group box 1 protein-induced lung inflammation and injury and improves survival in sepsis. Am J Physiol Lung Cell Mol Physiol 2005; 289(4): L583-90.

13. Abe T, Oka M, Tangoku A, et al. Interleukin-6 production in lung tissue after transthoracic esophagectomy. J Am Coll Surg 2001; 192(3): 322-9

14. Azim K, McManus R, Brophy K, et al. Genetic polymorphisms and the risk of infection following esophagectomy. positive association with TNF-alpha gene -308 genotype. Annals of surgery 2007; 246(1): 122-8

15. Chang YH, Lee DS, Jo HS, et al. Tumor necrosis factor alpha promoter polymorphism associated with increased susceptibility to secondary hemophagocytic lymphohistiocytosis in the Korean population. Cytokine 2006; 36(1-2): 45-50.

16. Allen ML, Hoschtitzky JA, Peters MJ, et al. Interleukin-10 and its role in clinical immunoparalysis following pediatric cardiac surgery. Critical care medicine 2006; 34(10): 2658-65.

17. Sainz J, Perez E, Gomez-Lopera S, et al. Genetic variants of IL6 gene promoter influence on C-reactive protein levels but are not associated with susceptibility to invasive pulmonary aspergillosis in haematological patients. Cytokine 2008; 41(3): 268-78.

18. Watanabe E, Hirasawa H, Oda S, et al. Cytokine-related genotypic differences in peak interleukin-6 blood levels of patients with SIRS and septic complications. J Trauma 2005; 59(5): 1181-9; discussion 89-90.

19. Ferrari SL, Ahn-Luong L, Garnero P, Humphries SE, Greenspan SL. Two promoter polymorphisms regulating interleukin-6 gene expression are associated with circulating levels of $\mathrm{C}$-reactive protein and markers of bone resorption in postmenopausal women. J Clin Endocrinol Metab 2003; 88(1): 255-9.

20. Lowe PR, Galley HF, Abdel-Fattah A, Webster NR. Influence of interleukin-10 polymorphisms on interleukin-10 expression and survival in critically ill patients. Critical care medicine 2003; 31(1): 34-8.

21. Silkov AN, Sennikova NS, Goreva EP, Lopatnikova YA, Sennikov SV. Production of TNF-alpha and IL-1beta by peripheral blood mononuclear cells in carriers of different allele variants of the gene. Bull Exp Biol Med 2012; 153(1): 68-71.

22. Soga $Y$, Nishimura $F$, Ohyama $H$, et al. Tumor necrosis factor-alpha gene (TNF-alpha) -1031/-863, -857 single-nucleotide polymorphisms (SNPs) are associated with severe adult periodontitis in Japanese. J Clin Periodontol 2003; 30(6): 524-31.

23. Wang L, Hirayasu K, Ishizawa M, Kobayashi Y. Purification of genomic DNA from human whole blood by isopropanolfractionation with concentrated $\mathrm{Nal}$ and SDS. Nucleic Acids Res 1994; 22(9): 1774-5.

24. Hamajima N, Saito T, Matsuo K, et al. Polymerase chain reaction with confronting two-pair primers for polymorphism genotyping. Jpn J Cancer Res 2000; 91(9): 865-8.

25. Ye S, Dhillon S, Ke X, Collins AR, Day IN. An efficient procedure for genotyping single nucleotide polymorphisms. Nucleic Acids Res 2001; 29(17): E88-8

26. Okayama N, Fujimura K, Nakamura J, et al. Evaluation of a new efficient procedure for single-nucleotide polymorphism genotyping: tetra-primer amplification refractory mutation system-polymerase chain reaction. Clin Chem Lab Med 2004; 42(1): 13-6.

27. Thomassen MJ, Divis LT, Fisher CJ. Regulation of human alveolar macrophage inflammatory cytokine production by interleukin-10. Clin Immunol Immunopathol 1996; 80(3 Pt 1): 321-4.

28. Wilkes DS, Neimeier M, Mathur PN, et al. Effect of human lung allograft alveolar macrophages on IgG production: immunoregulatory role of interleukin-10, transforming growth factor-beta, and interleukin-6. Am J Respir Cell Mol Biol 1995; 13(5): 621-8.

29. Toossi Z, Hirsch CS, Hamilton BD, et al. Decreased production of TGF-beta 1 by human alveolar macrophages compared with blood monocytes. J Immunol 1996; 156(9): 3461-8.

30. Morita K. The Effects of One-Lung Ventilation on Cytokine Production from Lung Tissue of Rat Is One-Lung Ventilation Reasonable for Thoracic Surgery? Bull Yamaguchi Med Sch 2003; 50: $65-75$

31. Donnelly SC, Strieter RM, Reid PT, et al. The association between mortality rates and decreased concentrations of interleukin-10 and interleukin-1 receptor antagonist in the lung fluids of patients with the adult respiratory distress syndrome. Ann Intern Med 1996; 125(3): 191-6.

32. Wang E, Simard M, Ouellet N, et al. Modulation of cytokines and chemokines, limited pulmonary vascular bed permeability, and prevention of septicemia and death with ceftriaxone and interleukin-10 in pneumococcal pneumonia. J Infect Dis 2000; 182(4): 1255-9.

33. Nakada TA, Hirasawa $\mathrm{H}$, Oda $\mathrm{S}$, et al. Influence of toll-like receptor 4, CD14, tumor necrosis factor, and interleukine-10 gene polymorphisms on clinical outcome in Japanese critically ill patients. J Surg Res 2005; 129(2): 322-8.

34. Mira JP, Cariou A, Grall F, et al. Association of TNF2, a TNF-alpha promoter polymorphism, with septic shock susceptibility and mortality: a multicenter study. Jama 1999; 282(6): 561-8.

35. Waterer GW, Quasney MW, Cantor RM, Wunderink RG. Septic shock and respiratory failure in community-acquired pneumonia have different TNF polymorphism associations. American journal of respiratory and critical care medicine 2001; 163(7): 1599-604.

36. Furuta M, Yano Y, Ito K, et al. Relationship of the tumor necrosis factor-alpha $-308 \mathrm{~A} / \mathrm{G}$ promoter polymorphism with insulin sensitivity and abdominal fat distribution in Japanese patients with type 2 diabetes mellitus. Diabetes research and clinical practice 2002; 56(2): $141-5$.

37. Turner DM, Williams DM, Sankaran D, et al. An investigation of polymorphism in the interleukin-10 gene promoter. Eur J Immunogenet 1997; 24(1): 1-8.

38. Shimada H, Ochiai T, Okazumi S, et al. Clinical benefits of steroid therapy on surgical stress in patients with esophageal cancer. Surgery 2000; 128(5): 791-8. 